\title{
ORBIS: unha análise da era das migracións usando un modelo xeoespacial da rede de comunicacións romana ORBIS: An analysis of the migration era using a geospatial model of the Roman communications network
}

Resumo: No presente traballo analizarase o asentamento dos godos no 418 na provincia romana da Aquitania, así como a mentalidade espacial romana, á luz dos modelos de conectividade do mundo romano xerados polo programa da Stanford University, ORBIS.

Palabras clave: ORBIS; romanos; godos; conectividade; espazo; Aquitania.

Abstract: This paper analyses the Gothic settlement of 418 AD in the Roman province of Aquitaine, looking in particular at Roman spatial perception, through the models of connectivity of the Roman world created using the ORBIS program, developed at Stanford University.

Keywords: ORBIS; Romans; Goths; Connectivity; Space; Aquitaine.

\section{Introdución}

Neste traballo postúlase que a capacidade do programa ORBIS para xerar representacións gráficas que priorizan os itinerarios, a conectividade e o fluxo das rutas -chegando a deformar o espazo físico- non só nos fornece con datos estadísticos, senón que xera unhas representacións do espazo que están moito máis en liña coa mentalidade espacial que imperaba na época das invasións que os mapas usados habitualmente. Isto, á súa vez, permite analizar determinados sucesos desta época tendo en conta a relación dos protagonistas implicados co espazo que os rodeaba naquel determinado momento histórico; no caso que nos ocupa, analizarase o asentamento godo na Aquitania.

Héctor Paleo Paz, Universidade de Santiago de Compostela

2 Open Access. (C) 2019 Héctor Paleo Paz, published by De Gruyter. (c) BY-NC-ND This work is licensed under the Creative Commons Attribution-NonCommercial-NoDerivatives 4.0 License. https://doi.org/10.1515/9783110585421-012 


\section{ORBIS}

O ORBIS é un programa que xera un modelo global de conectividade do mundo romano, onde permite analizar os patróns de comunicación en termos de tempo e custo simulando o movemento a través dunha versión sintética do conxunto das calzadas romanas, dos ríos navegables e das rutas marítimas. Para conseguir isto integra un conxunto de elementos estruturais fixos e unha serie de elementos variables e modulables, ofertando fundamentalmente tres tipos de instrumentos. Por un lado, un xerador de rutas entre localizacións do imperio. Créanse, concretamente, tres tipos de rutas, modulables coa introdución de factores humanos -e.g. o tipo de transporte-: a máis rápida, a máis curta e a máis barata, en función do que se queira priorizar. Por outro lado, un xerador de redes de conectividade, que crea unha simulación da conectividade específica dun sitio en concreto en relación coa súa contorna. E, por último, un xerador de diagramas de fluxo, que permite simular a cantidade de itinerarios que parten dun determinado punto e o lugar cara a onde se dirixen (Scheidel 2013; Scheidel 2014).

O obxectivo, por tanto, de Walter Scheidel e o seu equipo foi a creación dun programa que xere un modelo de conectividade global do mundo romano. Trátase dun patrón conscientemente xenérico que xira, tanto por necesidade como por decisión propia, arredor de tres características, as cales se deben asumir para comprender que problemas históricos se poden resolver con esta ferramenta. En primeiro lugar, o ORBIS pretende crear unha perspectiva a vista de paxaro, centrada no conxunto do sistema de comunicacións romano. O seu obxectivo non é estudar unha zona concreta do imperio de forma intensiva, senón a totalidade do mesmo de xeito extensivo. Por tanto, canto maior é a distancia que se busque simular e analizar, maior é a precisión; pola contra, perderá eficacia canto menor sexa a distancia. En segundo lugar, ten unha natureza sintética; ignóranse variables rexionais e ponse o foco nas principais arterias de comunicación. E, en terceiro lugar, posúe unha natureza xenérica; non se están a simular ou a recrear casos de viaxes concretas, senón que se pretende simular unha media estatística que, de forma acumulativa, forme o sistema. Por tanto, as preguntas que se lle deben facer a este programa deben ser as axeitadas (ORBIS: The Stanford Geospatial Network Model of the Roman World).

\section{Espazo e mapas no baixo Imperio Romano e o seu reflexo no ORBIS}

Para intentar demostrar a primeira parte da tese que se presenta neste traballo -que as representacións gráficas xeradas polo ORBIS están moito máis en liña 
coa mentalidade espacial romana- debemos definir, obviamente, cal é esta mentalidade espacial. Dunha forma sucinta, existían tres grandes disciplinas a través das cales os romanos abordaban o estudo do espazo que os rodeaba; a geographia, a corographia, e a agrimensio (Whittaker 2004: 63). A geographia, ou ges periodos, era o estudo e representación das terras no seu contexto cósmico; fora unha rama moi desenvolta polos gregos e bastante ignorada polos romanos, dado que aceptaban premisas gregas pero non profundaron no seu estudo (Whittaker 2002: 82). A súa principal manifestación gráfica foron os mapa mundi, representacións da oikoumene nas que se podían ver tres continentes e os seus diferentes climata, e que en todo caso non teñen por obxectivo orientarse na práctica (Brotton 2012: 17-53). A súa influencia no mundo romano é relativa aínda que está presente; pode percibirse, por exemplo, na tendencia a equiparar territorios con figuras xeométricas -é o caso de César, que compara a illa de Gran Bretaña cun triángulo (Whittaker 2004: 65)-. Estes mapas, para Polibio, permiten contextualizar lugares descoñecidos na mente e teñen unha forte tendencia eurocéntrica e romanocéntrica, como manifestacións simbólicas do poder e do goberno sen grandes detalles xeográficos (Whittaker 2004: 65; Brotton 2012: 9).

Pola súa parte, a chorografia foi unha disciplina moi desenvolta polos romanos que consiste na descrición detallada dos territorios (Clarke 1999: 128). A diferenza da xeografía parte da visión "horizontal” que os romanos teñen dos lugares, dos loci; normalmente, as descricións dos territorios realízanse cunha linguaxe que sitúa o espectador mirando o terreo de fronte, horizontalmente (Clarke 1999: 93). Exemplos disto poden atoparse en Tito Livio, cando describe a Haníbal observando a planicie italiana dende os Alpes, ou en César, describindo as Galias dende a Provenza, horizontalmente e a través de itinerarios (Whittaker 2004: 67). Unha das manifestacións máis claras desta tradición corográfica son os itinerarios, os cales teñen un gran peso na conformación da mentalidade espacial romana, como mencionaremos máis adiante.

Por último, temos a agrimensio, unha rama da topografía moi vinculada coa administración territorial e a explotación económica do territorio, que se ocupa da delimitación de superficies. Esta disciplina tivo unha grande importancia na vida legal do imperio e na distribución económica dos terreos (Dilke 1962: 170180; Whittaker 2004: 69).

Deste modo, falar da mentalidade espacial romana é falar esencialmente dos itinerarios. Estes eran listados de calzadas onde se inserían diferentes loci, marcando as distancias que había entre eles (Bunson 2002: 279). Podían ser tanto escritos coma debuxados, aínda que habitualmente combinaba ambas as dúas formas. Debido á súa popularidade, existían itinerarios oficiais e privados, e o seu uso era tanto civil -moi vinculado co cursus publicus - coma militar, cunha grande importancia loxística e estratéxica; tanto é así, que o manual de Vexecio non fala de 
mapas, senón de rutas ou itinera picta (Whittaker 2004: 71). A propia natureza destes sufriu unha transformación na época baixo imperial cando, debido á reinvención do homo viator clásico derivada do cristianismo, as peregrinacións experimentaron un aumento substancial; isto provocou que os itinerarios, ata entón máis locais, se integrasen formando redes simbólicas de carácter universal (Whittaker 2004: 72-73).

A súa influencia na concepción espacial dos romanos é enorme, e maniféstase fundamentalmente en tres cuestións. En primeiro lugar, a representación "hodolóxica” implica que os romanos experimentaran o espazo, en xeral, a través de liñas. É unha visión distinta á actual, moito máis baseada nas formas e superficies. Dun xeito simple, vían a relación entre lugares dunha forma unidimensional; é dicir, se dende o punto A se pode chegar ao punto B e ao punto $\mathrm{C}$, o mapa mental que farían os romanos tería en conta estas dúas rutas, pero non triangularían a distancia entre os tres puntos integrando a información nunha superficie (Whittaker 2004: 76-77). Isto non quere dicir que os romanos non fosen capaces de facer abstraccións espaciais con superficies en mente -un exemplo disto serían os procesos de centuriación-, transcendendo as liñas; simplemente implica que non era a súa forma fundamental de experimentar o espazo. En segundo lugar, a centralidade da rede urbana e viaria na concepción espacial romana queda patente naquilo que deciden representar nos propios itinerarios; consisten, fundamentalmente, en lugares ben vinculados coa vida urbana, ben ligados ao cursus publicus -cidades, villae, mansiones e mutationes-, e das rutas que os unen. Estes loci terían a súa posición determinada en relación coa súa localización nas vías de comunicación romanas e non pola súa posición nun punto concreto da superficie terrestre. Por último, a deformación xeográfica é simplemente unha consecuencia directa de todas as demais cualidades, combinada entre outras cousas coa síndrome do Omphalos, segundo a cal se reforza a importancia de Roma a través da súa posición central na representación (Whittaker 2004: 76-82).

Pois ben, son estes tres elementos que acabamos de analizar os que, ao estar nitidamente replicados no ORBIS, nos levaron a concluír que as representacións gráficas que xera están moito máis en liña coa mentalidade espacial romana que os mapas habituais; unha hipótese, por outra parte, da que tamén parten os propios deseñadores da aplicación (Padilla Peralta 2015). Literalmente, estamos ante unha simulación "hodolóxica" do mundo romano, onde se priorizan as principais arterias de comunicación e a rede urbana como elementos integradores do imperio, e onde se xeran unha serie de representacións gráficas que deforman o terreo xeográfico en base ao criterio de conectividade. Un exemplo disto pode observarse na comparación entre algunhas das deformacións xeográficas xeradas polo ORBIS e as que se poden ver na famosa Tabula Peutinger (Figura 11.1).

Este “mapa”, duns 30 centímetros de alto e case 7 metros de longo, comprime o mundo coñecido dende Hispania ata a India. Dende unha perspectiva xeográfica, é difícil imaxinar algo máis distorsionado; non obstante, os itinerarios que forman 


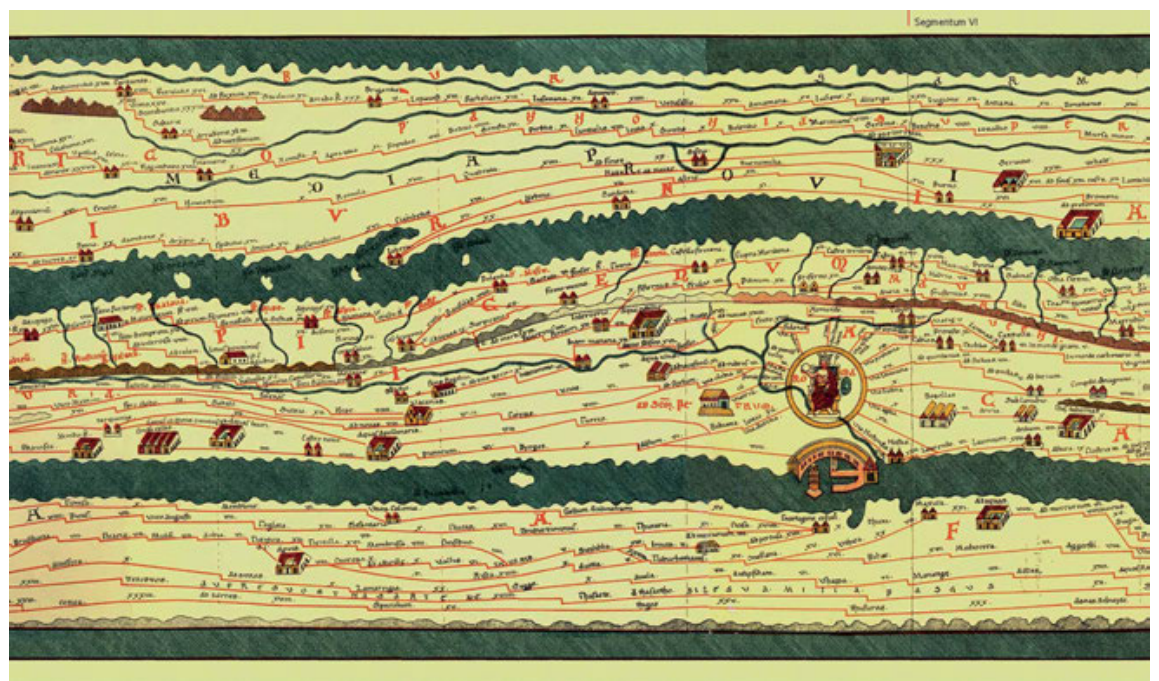

Figura 11.1: Tabula Peutinger

o cursus publicus están representados cun alto grao de detalle. Moitas destas distorsións son conxunturais e débense ao medio onde se está a representar o mundo; outras, non obstante, consideramos que se deben tamén á mentalidade espacial romana. Así, Cartago, que cos seus envíos de trigo se podía considerar o celeiro de Roma (Stone 2014), está moi preto da capital imperial, reducindo a distancia entre ambas as cidades dunha forma substancial. Esta distorsión é moi similar á que podemos observar se, co ORBIS, xeramos unha representación das redes de conectividade -network- da cidade de Roma (Figura 11.2).

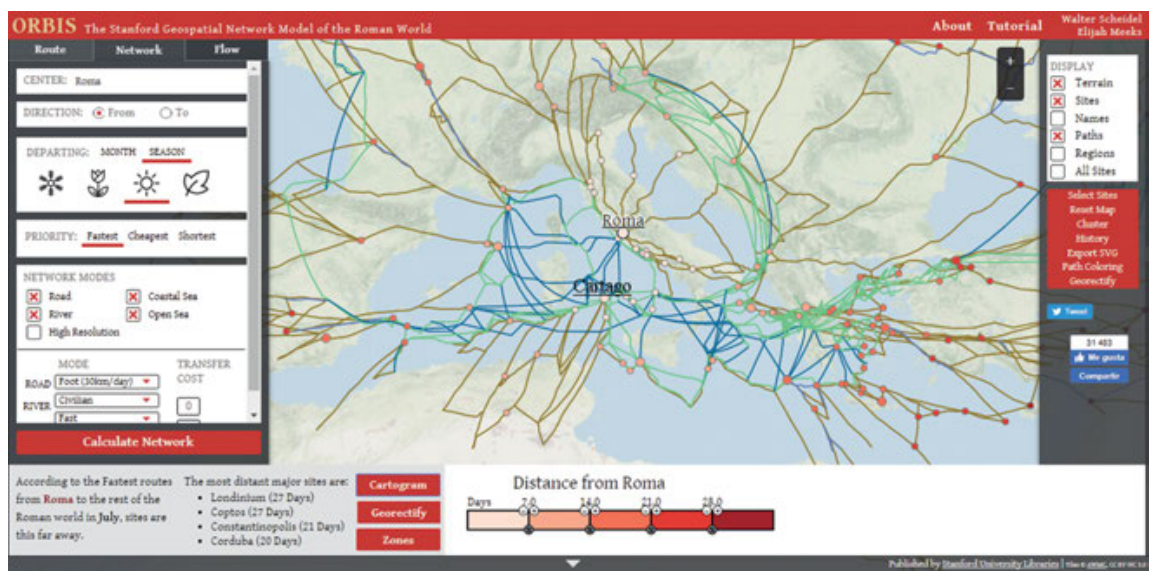

Figura 11.2: Rede de conectividade de Roma con respecto a Cartago 
Algo semellante sucede se analizamos a conectividade dende Londinium, o que achega as illas británicas e a Gallaecia dunha forma evidente (Figura 11.3).

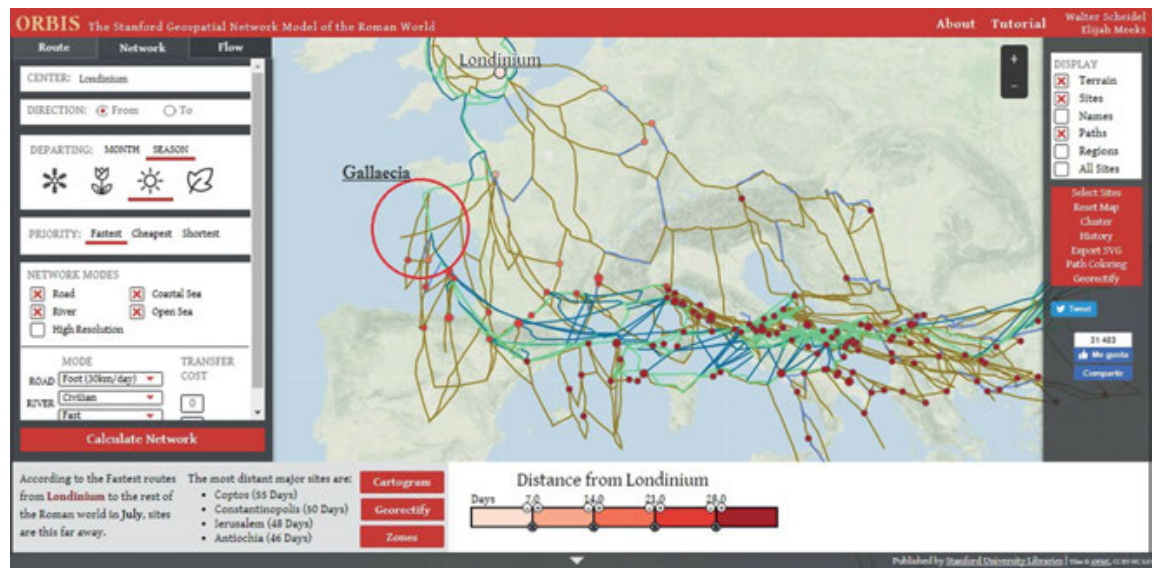

Figura 11.3: Rede de conectividade de Londinium con respecto á Gallaecia

Obviamente, estas deformacións non son as mesmas que se poden percibir nos mapas clásicos, pero a tendencia a priorizar as conexións por encima das distancias e das superficies é clara.

\section{As invasións xermánicas á luz do ORBIS; o caso dos godos na Aquitania}

Inicialmente, a aplicación do ORBIS no caso das invasións xermánicas pode parecer problemática porque semella incumprir dúas das tres características antes mencionadas. Por un lado, as migracións xermánicas -sexa cal sexa na que un se decida centrar- son un caso concreto, e por outro, non afecta á totalidade do Imperio, senón a unha parte concreta. Ademais, as fontes son confusas e incompletas con respecto ao percorrido que realizaron os diferentes pobos; a propia natureza deste percorrido, aínda coñecéndoo, é problemática para unha simulación ou unha análise a través do ORBIS, pois estes periplos tiñan moito máis de conxuntural que de planificado (Goffart 2009: 23-41). Non obstante, isto non inhabilita o ORBIS como un instrumento de traballo válido para estudar este proceso histórico; a clave está en saber que preguntas facerlle. Iso foi precisamente o que nos levou a escoller o caso do asentamento godo na Aquitania no 
418, pois máis que estudar a ruta que os levou alí, analizaremos a conectividade da rexión onde se asentan para resolver unha serie de dúbidas con respecto deste evento.

A cuestión histórica que se pretende abordar é por que o imperio romano, nun momento de poder relativo como é o mandato tácito de Constancio, decidiu realizar un pacto cos godos e asentalos nesta rexión concreta. Esta última cuestión deu lugar a un acalorado debate doutrinal (Halsall 2007: 230), e o que se pretende facer usando o ORBIS é observar se unha análise da conectividade da rexión pode aportar argumentos a favor ou en contra das diferentes hipóteses que existen.

Para analizar o asentamento godo na Aquitania é importante ter en conta que se produce nun contexto de contraataque imperial, non de debilidade. A primeira década do século $\mathrm{V}$ é, efectivamente, un período especialmente problemático para Roma, un contexto de guerra civil e usurpación no que se produce unha constante mobilización das tropas para tratar asuntos de política interna (Wickham 2009: 80). A maiores, os godos de Alarico estaban premendo ao imperio en Italia, chegando a saquear a propia Roma no ano 410. É nestes anos - concretamente, no 406- cando se produce a invasión das Galias por parte de grupos de vándalos -hasdingos e silingos-, alanos e suevos. Tras ser contidos no norte das Galias durante un tempo, conseguen avanzar cara ao sur ata cruzar os Pirenos e entrar en Hispania no 409. No 411 prodúcese a división -a través dun relativo consenso- da Península Ibérica entre as forzas invasoras; neste reparto, os alanos levan a parte do león, quedando con dúas provincias, a Cartaxinense e a Lusitania, os vándalos silingos quedan coa Bética, e os suevos e vándalos hasdingos fanse coa Gallaecia (Heather 2005: 271).

Non obstante, tal e como xa se mencionou, na segunda década do século V, as tornas cambian a favor de Roma; estamos ante unha década de fortalecemento e contraataque do poder imperial (Wickham 2009: 80). Cara ao 410/411 Flavio Constancio asume o papel de comandante supremo -magister militum - do Imperio de Occidente e estabiliza a situación a través dunha acertada combinación de forza militar e diplomacia. Así, en primeiro lugar acaba cos intentos de usurpación que ameazaban ao Emperador Honorio, e, por outra banda, preme aos godos de tal forma que os forza, mortos Alarico e Ataúlfo, a unha alianza co Imperio. No 416 usa esta forza combinada para atacar os pobos xermánicos asentados en Hispania e sometelos a unha contundente derrota. Os alanos, a principal forza inimiga, son derrotados completamente, ao igual que os vándalos silingos; só as posicións dos suevos e dos vándalos hasdingos quedan relativamente intactas na Gallaecia (Heather 2005: 310). 
É nesta situación -con Hispania maioritariamente baixo control de Roma e o imperio nunha posición de poder- cando se produce o asentamento dos godos na Aquitania; obviamente, os motivos políticos para a realización do pacto neste determinado momento non se van clarificar a través do ORBIS. Non obstante, si existen hipóteses que recalcan a elección de Aquitania II polo seu valor estratéxico, e estas teorías -de, entre outros, Kulikowski, Halsall e Heather- (Halsall 2007: 230) si se poden ver reforzadas por unha serie de modelos de conectividade que se poden crear no ORBIS. Para estes autores, a posición de Aquitania II é estratexicamente importante por diferentes motivos; por un lado, está o suficientemente preto de Hispania como para que os continxentes godos poidan mobilizarse e acudir como reforzo do exército imperial en caso de que -como efectivamente sucedeu- se realizasen novas campañas contra os únicos pobos xermánicos que non se venceran e que nese momento estaban asentados na provincia da Gallaecia: suevos e vándalos hasdingos (Heather 1996: 182). Por outro, está o bastante próxima a Ravena como para poder reforzar as tropas leais ao emperador e a Constancio en caso de que existise un intento de usurpación, pero non tanto como para premer ás autoridades imperiais dunha forma similar a como sucedera con Alarico (Halsall 2007: 230-234). A maiores, está o relativamente cerca das zonas controladas polos bagaudas ao norte do Loira como para poder reforzar as tropas imperiais en caso de que fixese falta (Heather 1996: 182). E por último, está situada nunha zona estratéxica dentro das Galias para poder asegurar a lealdade da rexión e controlar as importantes zonas de paso (Halsall 2007: 230-234). Pois ben, como se pode observar ao usar as opcións do ORBIS para xerar redes de conectividade e diagramas de fluxo, a importancia estratéxica desta rexión resulta incontestable (Figura 11.4 e Figura 11.5).

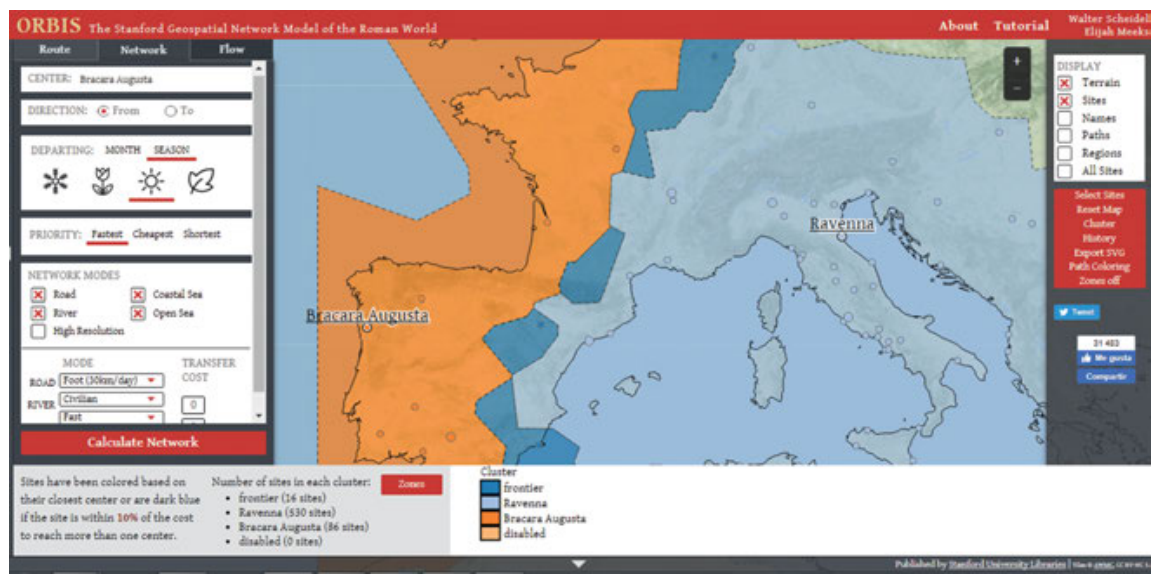

Figura 11.4: Cluster de dous mapas de conectividade -un co seu centro en Bracara Augusta e outro en Ravena- representando máis escuras as áreas onde esta se superpón. 


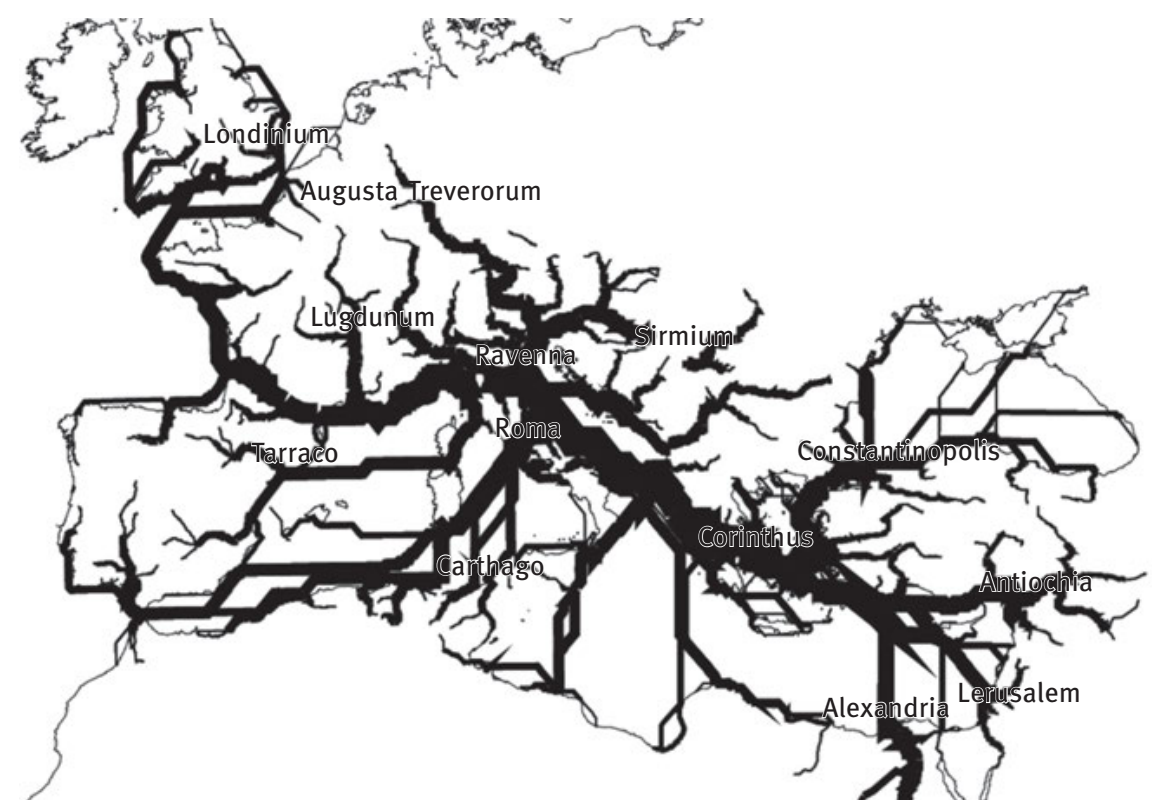

Figura 11.5: Mapa do fluxo comunicativo saínte de Ravena, onde se pode percibir a importancia do ramal aquitano.

Así, a través destas opcións podemos percibir: (a) unha importante conectividade cos puntos de interese político do momento; (b) o feito de que esteamos ante unha rexión de fronteira entre Bracara Augusta - central na rexión da Gallaecia controlada por suevos e vándalos hasdingos- e Ravena -sede do poder imperial-; (c) unha boa conectividade co norte das Galias; (d) un enorme fluxo comunicativo derivado da importancia desta rexión nas principais vías de comunicación do occidente imperial.

\section{Conclusión}

Por todo isto consideramos que o ORBIS permite abordar dúas cuestións que non adoitan ser facilmente conciliables. Por un lado, é unha ventá a un aspecto do mundo simbólico e cultural dunha determinada sociedade; a forma que tiñan os romanos de ver e relacionarse co espazo que os rodeaba. Por outro, é unha aplicación práctica e científica capaz de xerar datos estatísticos, modelos de conectividade e simulacións de ruta; instrumentos todos que serven para estudar elementos moito máis tanxibles como son as redes comerciais antigas ou, como 
vimos, a posición estratéxica dunha determinada rexión. Polo tanto, para que nos dea estas respostas o único que hai facer é saber que preguntarlle.

\section{Referencias bibliográficas}

Brotton, Jerry (2012): A History of the World in 12 Maps. London: Penguin Books.

Budson, Matthew (2002): Encyclopedia of the Roman World. New York: Facts on File, Inc.

Clarke, Katherine (1999): Between Geography and History. Hellenistic Constructions of the Roman World, Oxford: Clarendon Press.

Dilke, Oswald Ashton Wentworth (1962): “The Roman Surveyors”. En: Greece \& Rome, 9.2, pp. 170-180.

Goffar, W. (2009): Barbarians, maps, and historiography : studies on the early medieval West. Surrey: Routlege

Halsall, G. (2007): Barbarian migrations and the Roman West, 376-568. Cambridge: Cambridge University Press.

Heather, Peter J. (1996): The Goths. Oxford: Blackwell Publishers Ltd.

Heather, Peter J. (2005): La caída del imperio romano. Barcelona: Crítica.

ORBIS: The Stanford Geospatial Network Model of the Roman World. [En liña, http://orbis. stanford.edu/, consultado en 14/01/2018].

Padilla Peralta, Dan-el (2015): “ORBIS and the Ancient Itineraries: Preliminary Observations".

[En liña, http://orbis.stanford.edu/assets/Peralta_ORBISandAncientltineraries.pdf, consultado en 20/03/18].

Scheidel, W. and Meeks, E. (2012): ORBIS: The Stanford Geospatial Network Model of the Roman World. [En liña, http://orbis.stanford.edu/, consultado en 14/01/2018].

Scheidel, Walter (2013): “Explaining the Maritime Freight Charges in Diocletian's Prices Edict”. En: Journal of Roman Archaeology, 26, pp. 464-468.

Scheidel, Walter (2014): “The Shape of the Roman World”. En: Journal of Roman Archaeology, 27, pp. 7-32.

Stone, David L. (2014): "Africa in the Roman Empire: Connectivity, the Economy, and Artificial Port Structures”. En: American Journal of Archaeology, 118.4, pp. 565-600.

Whittaker, Charles R. (2002): “Mental maps: Seeing like a Roman”. En: Mckechnie, Paul (ed.): Thinking like a Lawyer: Essays on Legal History and General History for John Crook in his Eightieth Birthday. Boston: Brill Academic Club, pp. 81-112.

Whittaker, Charles R. (2004): Rome and its Frontier: The Dynamics of Empire. London: Routledge.

Wickham, Chris (2009): The Inheritance of Rome: A History of Europe form 400 to 1000. London: Penguin Book. 